OPEN ACCESS

Edited by:

Vincenza Cifarelli,

Washington University in St. Louis,

United States

Reviewed by:

Joseph M. Rutkowski,

Texas A\&M University, United States

Sinem Karaman,

Wihuri Research Institute, Finland

*Correspondence:

R. Sathish Srinivasan

sathish-srinivasan@omrf.org

Specialty section:

This article was submitted to

Lipid and Fatty Acid Research,

a section of the journal

Frontiers in Physiology

Received: 02 October 2019

Accepted: 03 January 2020

Published: 22 January 2020

Citation:

Ho Y-C and Srinivasan RS (2020) Lymphatic Vasculature in Energy

Homeostasis and Obesity.

Front. Physiol. 11:3.

doi: 10.3389/fphys.2020.00003

\section{Lymphatic Vasculature in Energy Homeostasis and Obesity}

\author{
Yen-Chun $\mathrm{Ho}^{1}$ and R. Sathish Srinivasan ${ }^{1,2 *}$ \\ ${ }^{1}$ Cardiovascular Biology Research Program, Oklahoma Medical Research Foundation, Oklahoma City, OK, United States, \\ ${ }^{2}$ Department of Cell Biology, University of Oklahoma Health Sciences Center, Oklahoma City, OK, United States
}

Obesity is a leading cause of cardiovascular diseases and cancer. Body mass is regulated by the balance between energy uptake and energy expenditure. The etiology of obesity is determined by multiple factors including genetics, nutrient absorption, and inflammation. Lymphatic vasculature is starting to be appreciated as a critical modulator of metabolism and obesity. The primary function of lymphatic vasculature is to maintain interstitial fluid homeostasis. Lymphatic vessels absorb fluids that extravasate from blood vessels and return them to blood circulation. In addition, lymphatic vessels absorb digested lipids from the intestine and regulate inflammation. Hence, lymphatic vessels could be an exciting target for treating obesity. In this article, we will review our current understanding regarding the relationship between lymphatic vasculature and obesity, and highlight some open questions.

Keywords: Prox1, vegfc, neuropilin, lymphedema, lipedema, obesity, inflammation

\section{INTRODUCTION}

Obesity is a disease caused by energy imbalance (Hill et al., 2012; Tchernof and Despres, 2013). Appetite, food consumption and exercise are only some of the parameters that regulate energy balance. In fact, obesity is a polygenic disease, and its etiology is determined by multiple factors such as neural circuits, hormones, nutrient absorption, lipid storage, lipid metabolism and inflammation (Figure 1). Besides, obesity is a risk factor for cancer and cardiovascular diseases such as type 2 diabetes mellitus, hypertension, hypercholesterolemia, hyperlipidemia, coronary artery disease, and stroke. In the United States, it is estimated that one-third of adults and one-sixth of children are obese (Ogden et al., 2013; Cunningham et al., 2014). The economic impact of obesity is estimated to be more than $\$ 100$ billion per year in the United States alone (Hammond and Levine, 2010). Hence, better understanding of the mechanisms that regulate obesity and approaches to treat this disease are urgently needed. In this article, we will describe exciting new discoveries regarding the role of lymphatic vasculature in metabolic regulation and obesity.

\section{FUNCTIONS OF THE LYMPHATIC VASCULATURE}

Lymphatic vasculature absorbs interstitial fluid and returns it to blood circulation (Tammela and Alitalo, 2010; Geng et al., 2017). Lacteals are specialized lymphatic vessels in the intestine, which absorb digested lipids (Bernier-Latmani and Petrova, 2017; Petrova and Koh, 2018). Lymphatic vessels are also important for clearing low-density lipoprotein particles from the skin and arteries 


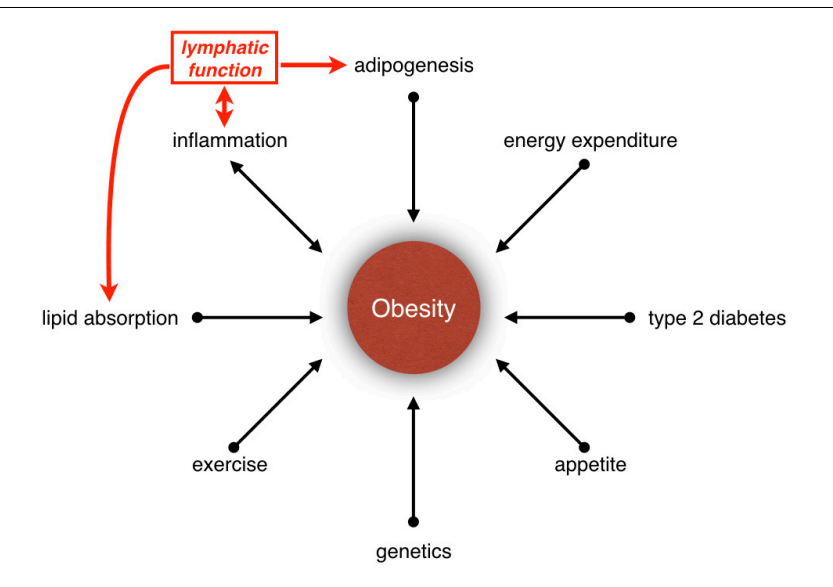

FIGURE 1 | Relationship between obesity and lymphatic vasculature. Obesity is influenced by many parameters, such as inflammation, lipid absorption, adipogenesis, type 2 diabetes, appetite, genetics, exercise, and energy expenditure. Increasing evidences have suggested that the lymphatic vasculature could be participating in the development of obesity by regulating lipid absorption, adipogenesis and inflammation.

by reverse cholesterol transport (Martel et al., 2013). Furthermore, lymphatic vasculature regulates the immune response (Randolph et al., 2005). Lymphatic endothelial cells (LECs) secrete cytokines such as CCL19 and CCL21 to recruit activated dendritic cells and transport them to lymph nodes to promote T- and B-cell activation (Randolph et al., 2005). LECs could directly present antigens to immune cells and promote peripheral immune tolerance (Rouhani et al., 2014). In summary, lymphatic vasculature regulates fluid homeostasis, lipid absorption, and immune response.

\section{LYMPHATIC VASCULAR ARCHITECTURE}

Lymphatic vasculature is made of LECs. LECs express unique markers that distinguish them from blood vascular endothelial cells. These markers include prospero-related homeobox 1 transcription factor (PROX1) (Wigle and Oliver, 1999), the tyrosine kinase receptor vascular endothelial growth factor 3 (VEGFR3/Flt4) (Kaipainen et al., 1995), the transmembrane O-glycoprotein podoplanin (Breiteneder-Geleff et al., 1999) and neuropilin 2 (NRP2) (Yuan et al., 2002). Endothelial cell junction proteins such as VE-cadherin, claudin-5, and PECAM-1 are expressed in all LECs. However, these junctional molecules are organized in different patterns to generate two functionally distinct structures within the lymphatic vasculature: lymphatic capillaries and collecting lymphatic vessels. Lymphatic capillaries have discontinuous "button-like junctions," which allows immune cells, interstitial fluid, and digested lipids to enter the vessels (Baluk et al., 2007; Yao et al., 2012). Lymphatic capillaries are connected to the surrounding tissues by anchoring filaments, which respond to changes in external fluid pressure by opening the button-like junctions to allow the entry of leukocytes and interstitial fluid into the vessels (Ikomi et al., 1996; Triacca et al., 2017). Unlike lymphatic capillaries, collecting vessels have continuous "zipper-like" endothelial junctions that prevent lymph leakage (Baluk et al., 2007; Yao et al., 2012). Collecting vessels are covered with continuous basement membrane and lymphatic muscle cells with contractile ability (Bridenbaugh et al., 2003; von der Weid and Zawieja, 2004; von der Weid, 2019). Collecting lymphatic vessels contain lymphatic valves (LVs), which regulate the unidirectional flow of lymph. Lymph flows through a series of lymph nodes where the immune cells and antigens are filtered out. Ultimately lymph is returned to blood circulation through two-pairs of lymphovenous valves (LVVs) located bilaterally at the junction of jugular and subclavian veins (Oliver and Srinivasan, 2008; Geng et al., 2017).

In the intestine, cholesterol, long-chain fatty acids, and fatsoluble vitamins are absorbed by intestinal epithelial cells, and repackaged in enterocytes into large (200-1000 nm) triglycerideloaded particles called "chylomicrons" (Tso and Balint, 1986; Zhang et al., 2018). Each intestinal villus contains a single lacteal, which is a lymphatic capillary with button-like junctions (Zhang et al., 2018). Most chylomicrons are absorbed by the lacteals, from which they are transported to submucosal and mesenteric collecting lymphatic vessels, then into the thoracic duct, and finally to the blood circulation (Oliver and Srinivasan, 2008; Randolph and Miller, 2014). Thus, digested lipids bypass the liver and are accessible to other organs and cells prior to the liver (Ahn and Park, 2016).

\section{LYMPHATIC VASCULAR DYSFUNCTION RESULTS IN LYMPHEDEMA}

Structural and functional defects of lymphatic vascular system can lead to lymphedema, which is characterized by localized accumulation of interstitial fluid and tissue swelling (Lohrmann et al., 2009). Although lymphedema is not a life-threatening disease, it could cause functional disability, skin infection, inflammation fibrosis and pain (Mehrara and Greene, 2014; Escobedo and Oliver, 2016; Breslin et al., 2018). Lymphedema is classified into either primary or secondary lymphedema. Primary lymphedema is caused by mutations in genes that regulate lymphatic vascular development. These genetic defects result in structural and functional defects in LECs, LVs, or LVVs. Primary lymphedema is typically present early in life (infancy, childhood, or puberty), and rarely appears in adulthood (older than age of 35) (Grada and Phillips, 2017). Secondary lymphedema is caused by surgery (removal of lymph nodes) or radiation therapy in cancer patients, infection or trauma. Secondary lymphedema is much more prevalent than primary lymphedema, and is an increasing clinical problem due to the improving survival rates of cancer patients (Whelan et al., 2015; Rockson et al., 2019).

\section{CLINICAL CORRELATIONS BETWEEN OBESITY AND LYMPHEDEMA}

There is reciprocal relationship between obesity and lymphatic dysfunction. Obesity is one of the risk factors for the development 
of secondary lymphedema in breast cancer patients (Werner et al., 1991; Helyer et al., 2010; Mehrara and Greene, 2014). In a study that compared 137 breast cancer patients, those with a body mass index (BMI) greater than 30 showed three times higher risk for developing upper extremity lymphedema compared with patients with lower BMI (Helyer et al., 2010). A similar result was observed in a second independent study involving 282 breast cancer patients (Werner et al., 1991).

Obesity could result in lymphedema in the absence of other risk factors such as primary lymphedema, inguinal lymphadenectomy or radiation treatment (Greene et al., 2012; Arngrim et al., 2013). In a study with a small cohort of 15 obese individuals, the average BMI of the patients with lymphedema (70.1) was much higher than the BMI of obese patients without lymphedema (42.0) (Greene et al., 2012). Another clinical study demonstrated that lean, healthy men (BMI: 22.3) showed better adipose tissue lymphatic drainage when compared with obese, but otherwise healthy men with normal glucose tolerance (BMI: around 35.7) (Arngrim et al., 2013).

Impaired lymphatic function could also lead to adipose tissue accumulation and fibrosis (Brorson, 2003). Secondary lymphedema patients tend to have higher BMI compared to breast cancer survivors without lymphedema (Ahmed et al., 2008). Lymphedema patients have more adipocytes in the edematous tissues. The edematous tissues are infiltrated with macrophages and lymphocytes, which promote the proliferation and hypertrophy of local adipocytes (Brorson, 2012; Ghanta et al., 2015). Adipose tissue-derived stem cells from lymphedema patients are more potent in their ability to undergo adipogenic differentiation in vitro when compared to cells derived from control patients (Levi et al., 2013). Taken together, these results suggest that chronic lymphedema creates an inflamed environment, which promotes adipose tissue accumulation (Cucchi et al., 2017). Nevertheless, lymphedema could reduce mobility and thereby reduce energy expenditure. Hence, is adipogenesis a direct outcome of lymphedema or is it indirectly caused by chronic immobility that is associated with lymphedema? This important question was addressed in part by recent studies, which have suggested that exercise (yoga, stretching, strength training) could improve breast cancer-related lymphedema (Baumann et al., 2018; Panchik et al., 2019). These studies must be very encouraging to lymphedema patients as they suggest that lymphedema-associated adipogenesis could be controlled by exercise.

\section{LIPEDEMA: A PAINFUL DISEASE THAT AFFECTS LYMPHATIC VASCULATURE AND ADIPOCYTES}

Lipedema is a disease characterized by the swelling of the legs due to the deposition of subcutaneous adipose tissue in the legs, thighs and buttocks (Torre et al., 2018). Most lipedema patients have high BMI, either in the overweight (25 to 30) or obese range (>30) (Fife et al., 2010). However, lipedema patients are less prone to type 2 diabetes mellitus, hypertension and dyslipidemia indicating that lipedema is distinct from obesity (Fonder et al., 2007; Al-Ghadban et al., 2019). Wold et al. proposed a series of criteria to diagnose lipedema in 1940s that is still in use (Child et al., 2010). These criteria include: (1) occurrence almost exclusively in women; (2) bilateral and symmetrical nature of adipose tissue accumulation with minimal involvement of the feet or ankle; (3) minimal pitting edema; (4) pain, tenderness and easy bruising; (5) persistent swelling of lower extremities despite elevation or weight loss (Child et al., 2010). The cause of lipedema is still unclear; however, there is evidence that hormonal and hereditary influence may play a role in the development of lipedema (Fonder et al., 2007). Important for this work, lipedema patients often show abnormal lymphoscintigraphic pattern with slow lymph flow (Bilancini et al., 1995). Ultrasound, MRI, and lymphangiogram are helpful for clinical diagnosis of lipedema (Warren Peled and Kappos, 2016). However, the test results may show "normal lymphatic function" in the early stage of the disorder (Fonder et al., 2007; Lohrmann et al., 2009; Child et al., 2010). Consequently, lipedema is often misdiagnosed as obesity (Fonder et al., 2007; Lohrmann et al., 2009; Godoy Mde et al., 2012; Shavit et al., 2018). Hence, whether lymphatic stasis in these patients cause increased adipogenesis or vice versa remains unknown.

\section{MOUSE MODELS THAT HIGHLIGHT THE ROLE OF LYMPHATIC VASCULATURE ON METABOLISM AND OBESITY}

As described in the previous sections, there is strong clinical correlation between lymphatic dysfunction and adipogenesis. In this section we will discuss evidence from mouse models, which allows us to determine causality.

\section{PROX1}

Prox1 heterozygous mice develop chylous ascites (leakage of lipid-rich lymph into the peritoneal cavity) soon after birth (Harvey et al., 2005). These Prox $1^{+/-}$mice develop adipocyte hypertrophy (increase in the size of adipocytes), increased serum free fatty acids, fatty liver and obesity in adulthood. Conditional deletion of one allele of Prox 1 from endothelial cells recapitulated this phenotype. In addition, overexpression of Prox 1 in the LECs rescues the obese phenotype of Prox 1 heterozygous mice (Escobedo et al., 2016). Furthermore, lymph could stimulate adipogenesis in vitro (Harvey et al., 2005). Together these results suggest that leakage of lymph triggers the onset of adipogenesis and obesity in Prox $1^{+/-}$mice (Harvey et al., 2005; Escobedo et al., 2016).

Obesity is mainly defined as a disease of energy imbalance. Young non-obese Prox $1^{+/-}$mice do not consume more food compared to their control littermates. In contrast, older obese Prox $1^{+/-}$mice consume less food and exercise less when compared with controls (Harvey et al., 2005). What promotes the transition between these metabolic states is currently unknown. Adipocyte inflammation is known to reduce energy expenditure and lower food consumption (Leibel et al., 1995; Zhao et al., 2018). Hence, it is possible that the adipocyte inflammation 
observed in Prox $1^{+/-}$mice (Harvey et al., 2005) might be contributing to the onset of obesity in older mice.

The obese phenotype of Prox $1^{+/-}$mice is strain dependent. Prox $1^{+/-}$and Tie2-Cre; Prox $1^{+/ f}$ mice bred in the NMRI background develop obesity (Harvey et al., 2005). However, conditional deletion of one allele of Prox 1 using lymphatic vasculature-specific Lyve1-Cre in a non-NMRI background does not result in obesity (Escobedo et al., 2016). The reason for this strain-specific onset of obesity remains to be determined. Nevertheless, PROX1 is expressed in many metabolism-related organs (see below). Hence, it is worth investigating whether PROX1 might be playing additional LEC-independent roles in regulating obesity.

PROX1 is necessary for the development of liver (SosaPineda et al., 2000; Seth et al., 2014). Obese Prox $1^{+/-}$mice develop hepatosteatosis (fatty liver disease) (Harvey et al., 2005). This observation is consistent with the fact that PROX1 is important for the maintenance of lipid homeostasis in the liver. In the hepatocytes PROX1 interacts with HDAC3 to down-regulate the expression of genes such as G0s2, Elovl6, $M f s d 2 a$, and Cidec, which are involved in lipid synthesis and lipolysis (Charest-Marcotte et al., 2010; Armour et al., 2017). Reducing PROX1 expression by AAV-based shRNA resulted in an increase in triglyceride levels in the mouse liver (Armour et al., 2017). In addition, treatment of mice with rapamycin causes hyperlipidemia by lowering PROX1 expression in the liver (Kwon et al., 2016).

PROX1 is important for the development of pancreatic endocrine cells and glucose metabolism. Conditional deletion of Prox 1 in pancreatic progenitors of mice showed delayed embryonic islet cell genesis and damage of ductal tissue in adulthood (Westmoreland et al., 2012). Overexpression of Prox 1 in immature $\beta$-cells promotes acute hyperglycemia (Paul et al., 2016). Consistent with these reports single-nucleotide polymorphisms in PROX1 are associated with higher fasting glucose levels and type 2 diabetes mellitus (Lecompte et al., 2013; Kretowski et al., 2015; Hamet et al., 2017; Adamska-Patruno et al., 2019). Furthermore, hyperinsulinemia is observed in obese Prox $1^{+/-}$mice (Harvey et al., 2005). However, whether it is due to lymphatic dysfunction or pancreatic defects is currently unknown. Insulin treatment is associated with weight gain in human patients (Russell-Jones and Khan, 2007). Hence, whether increased plasma insulin levels might contribute to obesity in Prox $1^{+/-}$mice could be investigated.

Skeletal muscle is an important tissue for glucose metabolism and fat (mainly free fatty acid) storage (Frontera and Ochala, 2015). Besides, metabolic rate of skeletal muscles is an important index of resting energy expenditure (Zurlo et al., 1990). Skeletal muscles are composed of slow muscle fibers and fast muscle fibers, which generate energy through aerobic and anaerobic mechanisms respectively. Obesity in humans is inversely correlated with proportion of slow muscle fibers (Wade et al., 1990). Prox1 is expressed in the satellite cells and slow muscle fibers. Conditional deletion of Prox 1 in skeletal muscles switched the slow muscle fibers to fast muscle fibers (Kivela et al., 2016). In contrast, overexpression of PROX1 converted fast muscle fibers to slow muscle fibers. These results suggest that
Prox 1 may play a critical metabolic role by regulating the identity of muscle fibers (Kivela et al., 2016).

Prox1 is expressed in brain regions, such as cortex, hippocampus, thalamus, hypothalamus, and cerebellum during embryonic and post-natal stages (Galeeva et al., 2007; Lavado and Oliver, 2007). Importantly, PROX1 is expressed in the paraventricular nucleus and the arcuate nucleus of the hypothalamus (Lavado and Oliver, 2007), which are directly involved in appetite control and feeding behavior (Formolo et al., 2019). Prox 1 is a key factor for granule cell formation, maturation and differentiation during developmental stages (Lavado et al., 2010). Prox 1 is important for adult neurogenesis in dentate gyrus and subventricular zone (Lavado et al., 2010; Bunk et al., 2016). However, whether PROX1 regulates the formation and/or functioning of the appetite centers of the brain remains to be investigated.

PROX1 is not expressed in retroperitoneal adipocytes (Harvey et al., 2005). However, PROX1 is reported to be expressed in subcutaneous and omental adipose tissues (Procino, 2014). Whether PROX1 is expressed in adipocyte progenitors and whether it could regulate adipocyte lineage in an epigenetic manner is unknown.

In summary, based on the known roles of PROX1 in metabolic tissues we are tempted to speculate that PROX1 might be controlling certain aspects of obesity in non-lymphatic tissues. Obesity has not been reported in mice that are heterozygous for Prox1 specifically in the liver, pancreas, brain, or muscle. Hence, it is possible that obesity arises in $\operatorname{Prox} 1^{+/-}$mice as a consequence of metabolic defects in multiple tissues as reported for another transcription regulator TRIM28 (Dalgaard et al., 2016). PROX1 regulates the expression of mitochondrial lipid transporter CPT1a in LECs (Wong et al., 2017). Through this metabolic pathway PROX1 promotes epigenetic changes that support lymphangiogenesis. Whether PROX1 regulates CPT1a expression in other tissues, and whether this pathway could contribute to the onset of obesity in Prox $1^{+/-}$mice needs to be evaluated.

\section{VEGF-C, VEGF-D, and VEGFR3}

VEGF-C/VEGFR3 signaling is critical for lymphatic vascular development. $V e g f c^{-/-}$mice lack lymphatic vessels due to a failure of LEC budding from the embryonic veins (Karkkainen et al., 2004; Hagerling et al., 2013). Mutations in VEGFR3 and $V E G F-C$ are associated with congenital lymphedema (Ferrell et al., 1998; Brice et al., 2005; Gordon et al., 2013). Subcutaneous fat is observed in Chy mice carrying an inactivating point mutation in the kinase domain of VEGFR3 (Karkkainen et al., 2001). However, obesity is not observed in Chy mice (Aspelund et al., 2016) indicating that obesity and adipogenesis are not necessarily correlated.

Deletion of $V e g f c$ in adult mice caused the regression of intestinal lacteals, reduced lipid absorption and provided resistance to high fat diet-induced obesity (Nurmi et al., 2015). Likewise, K14-VEGFR3-Ig mice in which a soluble form of extracellular VEGFR3 (sVEGFR3) that traps VEGF-C and VEGF-D was expressed from keratinocytes, were also resistant to high fat diet induced obesity, hepatic lipid accumulation 
and metabolic dysfunction (Karaman et al., 2015). In contrast, overexpression of VEGF-C in the keratinocytes resulted in weight gain, hepatic lipid accumulation, subcutaneous adipose tissue accumulation and insulin resistance even in chow diet fed mice (Karaman et al., 2016). Furthermore, an increased number of pro-inflammatory macrophages were found in the white adipose tissue of the VEGF-C overexpression mice (Karaman et al., 2016). These results suggest that the pro-lymphangiogenic VEGF-C is also a pro-inflammatory and pro-obesogenic molecule. These results are consistent with the observation that obese patients have elevated levels of VEGF-C in their serum (Silha et al., 2005; Wada et al., 2011).

Gut microbiota are important regulators of metabolism and energy balance (Nicholson et al., 2012; Chevalier et al., 2015). Depletion of gut microbiota leads to morphological defects in lacteals (Suh et al., 2019). Gut microbiota stimulates macrophages of the intestinal villi to produce VEGF-C. Lack of gut microbiota causes the transformation of button-like junctions of lacteals into zipper-like junctions due to reduced VEGF-C signaling (Suh et al., 2019). This junctional transformation reduced lipid absorption in the gut (Suh et al., 2019). Taken together, these results suggest that gut microbiota may play a role in obesity and metabolic syndrome by regulating VEGF-C signaling.

VEGF-D is an additional ligand of VEGFR3. Deletion of Vegfd in mice does not result in any obvious lymphatic defects (Baldwin et al., 2005). However, overexpression of VEGF-D can induce lymphangiogenesis and angiogenesis under normal and pathological conditions (Baldwin et al., 2005; Bui et al., 2016). Overexpression of VEGF-D in lungs, kidneys, and adipose tissue induces hyperplasia of lymphatic vessels and lymphangiectasia (Lammoglia et al., 2016). Moreover, longterm overexpression of VEGF-D in adipose tissue of mice caused increased macrophage infiltration and enhanced adipose tissue fibrosis (Lammoglia et al., 2016). However, overexpression VEGF-D did not result in obesity or insulin resistance in chow diet fed mice (Lammoglia et al., 2016). Surprisingly, in high-fat diet fed condition overexpression of VEGF-D in the adipocytes resulted in enhanced glucose clearance, lower insulin levels and reduced liver triglycerides (Chakraborty et al., 2019). Total F4/80 ${ }^{+}$macrophages were reduced in subcutaneous adipose tissue by increased immune trafficking from the tissue. These results suggest that enhanced VEGF-D signaling in the adipose tissue might reduce obesity associatedimmune cell accumulation and improve metabolic response (Chakraborty et al., 2019).

These unexpected and somewhat contradictory roles of VEGF-C, VEGF-D, and VEGFR3 call for further investigation of this signaling pathway in metabolic disorders and obesity.

\section{Neuropilin}

Neuropilins 1 and 2 (NRP1 and NRP2) were originally identified as molecules that are necessary for the patterning of neurons (Kitsukawa et al., 1995; Kolodkin et al., 1997). NRPs were found to function as co-receptors of VEGF-receptors in endothelial cells (Bouvree et al., 2012). NRP1 is mainly expressed in arteries and NRP2 is expressed in veins and lymphatic vessels (Herzog et al., 2001; Yuan et al., 2002). VEGF-A associates with NRP1/VEGFR1 complex to induce angiogenesis (Soker et al., 1998; Zhang et al., 2018). VEGF-C associates with NRP2/VEGFR2/VEGFR3 complex to regulate lymphangiogenesis (Favier et al., 2006; Bouvree et al., 2012; Deng et al., 2015). NRPs also interact with secreted and transmembrane ligands known as semaphorins (Kolodkin et al., 1997). There are eight classes of SEMA family (SEMA1-7; SEMAV); of which, SEMA3-7 are found in vertebrates (Neufeld and Kessler, 2008). NRPs can interact with members of SEMA3 family. SEMA3/NRP complexes further interact with transmembrane proteins called plexins. Plexins regulate the development of many organs, such as skeleton and kidney, and participate in angiogenesis and vascular patterning (Perala et al., 2012). SEMA3/NRP1/PlexinA1 complex regulates LV morphogenesis (Bouvree et al., 2012; Jurisic et al., 2012).

Nrp1 knockout mice are embryonic lethal at E12.5. Nrp1 $1^{-/-}$ mice exhibited vascular defects such as agenesis and transposition of great vessels, and disorganized and insufficient development of vascular networks in the yolk sac (Kawasaki et al., 1999). Global overexpression of Nrp1 results in ectopic blood vascular sprouting, dilated vessels, and abnormal heart (Kitsukawa et al., 1995).

Lacteals are made of LECs with discontinuous button-like junctions. These button-like junctions allow the easy passage of large chylomicrons into the lacteals. Deletion of Nrp1 or Vegfr1 by inducible endothelial- specific Cre resulted in the transition of button-like junctions of lacteals into zipper-like junctions (Zhang et al., 2018). Knock out of Nrp1 or Vegfr1 in blood endothelial cells enhances the bioavailability of VEGF-A and downstream signaling through VEGFR2 in LECs. High VEGFR2 signaling activity promotes zipper-like junctions in lacteals. Increased number of zipper-like junctions in mice lacking NRP1 or VEGFR1 reduced chylomicron uptake and also increased their resistance to high-fat diet-induced obesity (Zhang et al., 2018).

Nrp2-null mice are viable but have hypoplastic lymphatic capillaries compared with littermate controls (Yuan et al., 2002). Whether LEC-specific deletion of Nrp2 affects metabolism is currently not known.

Neuropilins and their ligands play an additional-complex role in energy homeostasis through the nervous system (van der Klaauw et al., 2019). Several variants of NRP1, NRP2, and SEMA3 are identified in severely obese individuals (van der Klaauw et al., 2019). These variants disrupt the secretion of melanocortin and/or signaling downstream of melanocortin4-receptor (MC4R) in human embryonic kidney 293 cells. In vivo melanocortin is released by pro-opiomelanocortin (POMC) or Neuropeptide Y (NPY)/Agouti-related protein (AgRP) positive neurons in hypothalamus. Melanocortin/MC4R signaling reduces food intake and increase energy expenditure (Cowley et al., 2001). Deletion of Nrp2 in POMC neurons reduces energy expenditure and causes weight gain (van der Klaauw et al., 2019). Hence, the lymphatic and nonlymphatic contribution of NRPs should also be dissected in the context of obesity.

\section{Apelin}

Apelin is a peptide and a ligand for the orphan G proteincoupled receptor AJP (Tatemoto et al., 1998). Apelin and AJP 
are widely expressed in the brain, intestine, kidney, adipose tissue and vasculature (Lee et al., 2000; Chen et al., 2003). Apelin/AJP signaling is involved in many physiological processes, including glucose homeostasis, lipid metabolism (Trayhurn et al., 2006), obesity (Boucher et al., 2005; Sawane et al., 2013), and diabetes (Li et al., 2006). High fat diet-fed $A p l n^{-/-}$mice were severely obese and had lymphatic and blood vasculature abnormalities (Sawane et al., 2013).

In vitro studies determined that Apelin could stabilize the expression of adherens junction protein VE-Cadherin and reduce fatty acid-induced vascular hyperpermeability (Sawane et al., 2013). These results suggest that Apelin maintains lymphatic vessel integrity, and inhibits dietary fat absorption and accumulation.

In summary, these observations suggest a context dependent role of lymphatic vasculature in regulating obesity. Nevertheless, additional non-LEC roles for these molecules in regulating metabolism cannot be excluded.

\section{MOUSE MODELS OF OBESITY WITH DEFECTIVE LYMPHATIC FUNCTION}

As mentioned previously, lymphatic function is abnormal in obese humans (Arngrim et al., 2013). The following mouse studies support those observations and provide mechanistic explanations for obesity-induced lymphatic dysfunction.

\section{Adipokines}

Adipocytes secrete signaling molecules such as leptin, adiponectin, and resistin. These signaling molecules are collectively known as adipokines. One of the primary functions of leptin is to activate nerve centers of the brain and promote satiety. $\mathrm{Ob} / \mathrm{Ob}$ mice, which lack leptin develop severe obesity and type 2 diabetes mellitus. Scallan et al. (2015) demonstrated that the lymphatic vessels of $\mathrm{Ob} / \mathrm{Ob}$ mice are dilated and leaky. They further showed that this lymphatic phenotype is due to low nitric oxide (NO) bioavailability (Scallan et al., 2015).

Adiponectin also plays a role in maintaining lymphatic function (Shimizu et al., 2013). Using tail-injury model Shimizu et al. demonstrated that mice lacking adiponectin were deficient in their ability to clear tissue fluid and had severe tail edema. In contrast, administration of adiponectin promoted the regrowth of lymphatic vessels and reduced edema. Mechanistically, adiponectin activated the phosphorylation of AKT and eNOS through AMPK and promoted the survival and proliferation of LECs. These data suggest that adipokines such as leptin and adiponectin act as modulators of lymphatic function.

\section{High-Fat Diet-Induced Obesity}

Several studies have investigated the influence of high fat diet induced obesity on lymphatic vascular function (Lim et al., 2009; Blum et al., 2014; Savetsky et al., 2014, 2015; Barton and Husmann, 2016; Garcia Nores et al., 2016; Hespe et al., 2016; Nitti et al., 2016; Torrisi et al., 2016). They overwhelmingly conclude that obesity affects lymphatic vascular formation and function.

High-fat diet aggravates hypercholesterolemia in $A p o E^{-/-}$ mice. Lymphatic vessels of these hypercholesterolemic mice were defective in their ability to take up interstitial fluid and were leaky (Lim et al., 2009). Moreover, collecting lymphatic vessels of these mice lacked smooth muscle cell coverage and had abnormal LVs (Lim et al., 2009). Therefore, hypercholesterolemia could inhibit the maturation of lymphatic vessels.

Weitman et al. (2013) demonstrated that high-fat dietinduced obesity resulted in impaired lymphatic fluid uptake and transport, reduced number of LECs in lymph nodes, dysregulated CCL21 gradient and defective immune cell trafficking. Similarly, Detmar and colleagues showed that high-fat diet impaired the contractility of lymphatic vessels and made them nonresponsive to mechanostimulation (Blum et al., 2014). Thus, high-fat diet could inhibit LEC survival or proliferation and could compromise lymphatic vascular function.

How could obesity affect lymphatic function? Using tailinjury model Detmar and colleagues quantified lymphatic function in high-fat diet-fed mice before they became obese (Gousopoulos et al., 2017). They determined that lymph transport is identical between control and high-fat diet-fed mice. This important observation indicated that increased number or size of adipocytes, but not serum lipids, is responsible for lymphatic dysfunction in obese mice. Obesity is associated with chronic, low-grade inflammation (Wellen and Hotamisligil, 2005). Savetsky et al. (2014, 2015) demonstrated that obesity-induced inflammation could compromise lymphatic function. In contrast, inhibition of inflammation increases lymphatic capillary density and restores lymphatic vascular function in high-fat diet-induced obese mice (Torrisi et al., 2016). Taken together, inflammation could play a key role in obesity-induced lymphatic dysfunction. Furthermore, lymphatic dysfunction could also exacerbate inflammation, thus setting up a vicious feedback loop (Figure 1). Compression or increased lymph load caused by adipocyte hypertrophy/hyperplasia could also affect lymphatic function.

\section{SUMMARY AND FUTURE DIRECTIONS}

Obesity is a complex disease that is influenced by many parameters (Figure 1). Evidence is clear that the lymphatic vasculature regulates lipid absorption, adipogenesis, and inflammation (Figure 1). It is also clear that obesity could affect lymphatic function. However, whether lymphatic dysfunction could cause obesity is not fully clear. Mouse studies have revealed that while some mutations that cause lymphatic vascular defects could promote obesity, other mutations protect against it. As proteins generally perform multiple functions it is possible that the genes that regulate lymphatic vascular development or functioning could independently regulate metabolism. Additionally, lymphedema causes severe pain and immobility in patients, which in turn could affect energy expenditure and 
cause weight gain. Due to these complexities carefully controlled clinical studies and mouse experiments are needed to better understand the relationship between lymphatic function and metabolic diseases. This knowledge could significantly impact the lives of millions of lymphedema, lipedema, and obesity patients worldwide.

\section{AUTHOR CONTRIBUTIONS}

Y-CH and RS designed, co-wrote, and coedited the manuscript.

\section{REFERENCES}

Adamska-Patruno, E., Godzien, J., Ciborowski, M., Samczuk, P., Bauer, W., Siewko, K., et al. (2019). The type 2 diabetes susceptibility PROX1 gene variants are associated with postprandial plasma metabolites profile in non-diabetic men. Nutrients 11:E882. doi: 10.3390/nu11040882

Ahmed, R. L., Prizment, A., Lazovich, D., Schmitz, K. H., and Folsom, A. R. (2008). Lymphedema and quality of life in breast cancer survivors: the Iowa Women's Health Study. J. Clin. Oncol. 26, 5689-5696. doi: 10.1200/JCO.2008.16. 4731

Ahn, H., and Park, J. H. (2016). Liposomal delivery systems for intestinal lymphatic drug transport. Biomater. Res. 20:36. doi: 10.1186/s40824-016-0083-1

Al-Ghadban, S., Cromer, W., Allen, M., Ussery, C., Badowski, M., Harris, D., et al. (2019). Dilated blood and lymphatic microvessels, angiogenesis, increased macrophages, and adipocyte hypertrophy in lipedema thigh skin and fat tissue. J. Obes. 2019:8747461. doi: 10.1155/2019/8747461

Armour, S. M., Remsberg, J. R., Damle, M., Sidoli, S., Ho, W. Y., Li, Z., et al. (2017). An HDAC3-PROX1 corepressor module acts on HNF4alpha to control hepatic triglycerides. Nat. Commun. 8:549. doi: 10.1038/s41467-017-00772-5

Arngrim, N., Simonsen, L., Holst, J. J., and Bulow, J. (2013). Reduced adipose tissue lymphatic drainage of macromolecules in obese subjects: a possible link between obesity and local tissue inflammation? Int. J. Obes. 37, 748-750. doi: 10.1038/ijo.2012.98

Aspelund, A., Robciuc, M. R., Karaman, S., Makinen, T., and Alitalo, K. (2016). Lymphatic system in cardiovascular medicine. Circ. Res. 118, 515-530. doi: 10.1161/CIRCRESAHA.115.306544

Baldwin, M. E., Halford, M. M., Roufail, S., Williams, R. A., Hibbs, M. L., Grail, D., et al. (2005). Vascular endothelial growth factor D is dispensable for development of the lymphatic system. Mol. Cell. Biol. 25, 2441-2449. doi: 10. 1128/MCB.25.6.2441-2449.2005

Baluk, P., Fuxe, J., Hashizume, H., Romano, T., Lashnits, E., Butz, S., et al. (2007). Functionally specialized junctions between endothelial cells of lymphatic vessels. J. Exp. Med. 204, 2349-2362. doi: 10.1084/jem.20062596

Barton, M., and Husmann, M. (2016). Obesity causes lymphatic vascular injury: time for clinical translation. J. Physiol. 594, 6807-6808. doi: 10.1113/JP273253

Baumann, F. T., Reike, A., Reimer, V., Schumann, M., Hallek, M., Taaffe, D. R., et al. (2018). Effects of physical exercise on breast cancer-related secondary lymphedema: a systematic review. Breast Cancer Res. Treat. 170, 1-13. doi: 10.1007/s10549-018-4725-y

Bernier-Latmani, J., and Petrova, T. V. (2017). Intestinal lymphatic vasculature: structure, mechanisms and functions. Nat. Rev. Gastroenterol. Hepatol. 14, 510-526. doi: 10.1038/nrgastro.2017.79

Bilancini, S., Lucchi, M., Tucci, S., and Eleuteri, P. (1995). Functional lymphatic alterations in patients suffering from lipedema. Angiology 46, 333-339. doi: $10.1177 / 000331979504600408$

Blum, K. S., Karaman, S., Proulx, S. T., Ochsenbein, A. M., Luciani, P., Leroux, J. C., et al. (2014). Chronic high-fat diet impairs collecting lymphatic vessel function in mice. PLoS One 9:e94713. doi: 10.1371/journal.pone.0094713

Boucher, J., Masri, B., Daviaud, D., Gesta, S., Guigne, C., Mazzucotelli, A., et al. (2005). Apelin, a newly identified adipokine up-regulated by insulin and obesity. Endocrinology 146, 1764-1771. doi: 10.1210/en.2004-1427

Bouvree, K., Brunet, I., Del Toro, R., Gordon, E., Prahst, C., Cristofaro, B., et al. (2012). Semaphorin $3 A$, Neuropilin-1, and PlexinA1 are required for lymphatic

\section{FUNDING}

This work was supported by NIH/NHLBI (R01HL131652 and R01HL133216 to RS) and American Heart Association (19POST34380819 to Y-CH).

\section{ACKNOWLEDGMENTS}

We thank Dr. Lorin Olson for his insightful suggestions and for editing this manuscript.

valve formation. Circ. Res. 111, 437-445. doi: 10.1161/CIRCRESAHA.112. 269316

Breiteneder-Geleff, S., Soleiman, A., Kowalski, H., Horvat, R., Amann, G., Kriehuber, E., et al. (1999). Angiosarcomas express mixed endothelial phenotypes of blood and lymphatic capillaries: podoplanin as a specific marker for lymphatic endothelium. Am. J. Pathol. 154, 385-394. doi: 10.1016/S00029440(10)65285-6

Breslin, J. W., Yang, Y., Scallan, J. P., Sweat, R. S., Adderley, S. P., and Murfee, W. L. (2018). Lymphatic vessel network structure and physiology. Compr. Physiol. 9 , 207-299. doi: 10.1002/cphy.c180015

Brice, G., Child, A. H., Evans, A., Bell, R., Mansour, S., Burnand, K., et al. (2005). Milroy disease and the VEGFR-3 mutation phenotype. J. Med. Genet. 42, 98-102. doi: 10.1136/jmg.2004.024802

Bridenbaugh, E. A., Gashev, A. A., and Zawieja, D. C. (2003). Lymphatic muscle: a review of contractile function. Lymphat. Res. Biol. 1, 147-158. doi: 10.1089/ 153968503321642633

Brorson, H. (2003). Liposuction in arm lymphedema treatment. Scand. J. Surg. 92, 287-295. doi: 10.1177/145749690309200409

Brorson, H. (2012). Liposuction normalizes - in contrast to other therapies lymphedema-induced adipose tissue hypertrophy. Handchir. Mikrochir. Plast. Chir. 44, 348-354. doi: 10.1055/s-0032-1323749

Bui, H. M., Enis, D., Robciuc, M. R., Nurmi, H. J., Cohen, J., Chen, M., et al. (2016). Proteolytic activation defines distinct lymphangiogenic mechanisms for VEGFC and VEGFD. J. Clin. Invest. 126, 2167-2180. doi: 10.1172/JCI83967

Bunk, E. C., Ertaylan, G., Ortega, F., Pavlou, M. A., Gonzalez Cano, L., Stergiopoulos, A., et al. (2016). Proxl is required for oligodendrocyte cell identity in adult neural stem cells of the subventricular zone. Stem Cells 34, 2115-2129. doi: 10.1002/stem.2374

Chakraborty, A., Barajas, S., Lammoglia, G. M., Reyna, A. J., Morley, T. S., Johnson, J. A., et al. (2019). Vascular endothelial growth factor-D (VEGF-D) overexpression and lymphatic expansion in murine adipose tissue improves metabolism in obesity. Am. J. Pathol. 189, 924-939. doi: 10.1016/j.ajpath.2018. 12.008

Charest-Marcotte, A., Dufour, C. R., Wilson, B. J., Tremblay, A. M., Eichner, L. J., Arlow, D. H., et al. (2010). The homeobox protein Proxl is a negative modulator of ERR\{alpha\}/PGC-1\{alpha\} bioenergetic functions. Genes Dev. 24, 537-542. doi: $10.1101 /$ gad.1871610

Chen, M. M., Ashley, E. A., Deng, D. X., Tsalenko, A., Deng, A., Tabibiazar, R., et al. (2003). Novel role for the potent endogenous inotrope apelin in human cardiac dysfunction. Circulation 108, 1432-1439. doi: 10.1161/01.CIR. 0000091235.94914 .75

Chevalier, C., Stojanovic, O., Colin, D. J., Suarez-Zamorano, N., Tarallo, V., VeyratDurebex, C., et al. (2015). Gut microbiota orchestrates energy homeostasis during cold. Cell 163, 1360-1374. doi: 10.1016/j.cell.2015.11.004

Child, A. H., Gordon, K. D., Sharpe, P., Brice, G., Ostergaard, P., Jeffery, S., et al. (2010). Lipedema: an inherited condition. Am. J. Med. Genet. A. 152A, 970-976. doi: 10.1002/ajmg.a.33313

Cowley, M. A., Smart, J. L., Rubinstein, M., Cerdan, M. G., Diano, S., Horvath, T. L., et al. (2001). Leptin activates anorexigenic POMC neurons through a neural network in the arcuate nucleus. Nature 411, 480-484. doi: 10.1038/35078085

Cucchi, F., Rossmeislova, L., Simonsen, L., Jensen, M. R., and Bulow, J. (2017). A vicious circle in chronic lymphoedema pathophysiology? An adipocentric view. Obes. Rev. 18, 1159-1169. doi: 10.1111/obr.12565 
Cunningham, S. A., Kramer, M. R., and Narayan, K. M. (2014). Incidence of childhood obesity in the United States. N. Engl. J. Med. 370, 403-411. doi: 10.1056/NEJMoa1309753

Dalgaard, K., Landgraf, K., Heyne, S., Lempradl, A., Longinotto, J., Gossens, K., et al. (2016). Trim 28 haploinsufficiency triggers Bi-stable epigenetic obesity. Cell 164, 353-364. doi: 10.1016/j.cell.2015.12.025

Deng, Y., Zhang, X., and Simons, M. (2015). Molecular controls of lymphatic VEGFR3 signaling. Arterioscler. Thromb. Vasc. Biol. 35, 421-429. doi: 10.1161/ ATVBAHA.114.304881

Escobedo, N., and Oliver, G. (2016). Lymphangiogenesis: origin, specification, and cell fate determination. Annu. Rev. Cell Dev. Biol. 32, 677-691. doi: 10.1146/ annurev-cellbio-111315-124944

Escobedo, N., Proulx, S. T., Karaman, S., Dillard, M. E., Johnson, N., Detmar, M., et al. (2016). Restoration of lymphatic function rescues obesity in Prox1haploinsufficient mice. JCI Insight 1:e85096. doi: 10.1172/jci.insight.85096

Favier, B., Alam, A., Barron, P., Bonnin, J., Laboudie, P., Fons, P., et al. (2006). Neuropilin-2 interacts with VEGFR-2 and VEGFR-3 and promotes human endothelial cell survival and migration. Blood 108, 1243-1250. doi: 10.1182/ blood-2005-11-4447

Ferrell, R. E., Levinson, K. L., Esman, J. H., Kimak, M. A., Lawrence, E. C., Barmada, M. M., et al. (1998). Hereditary lymphedema: evidence for linkage and genetic heterogeneity. Hum. Mol. Genet. 7, 2073-2078. doi: 10.1093/hmg/7.13. 2073

Fife, C. E., Maus, E. A., and Carter, M. J. (2010). Lipedema: a frequently misdiagnosed and misunderstood fatty deposition syndrome. Adv. Skin Wound Care 23, 81-92. doi: 10.1097/01.ASW.0000363503.92360.91

Fonder, M. A., Loveless, J. W., and Lazarus, G. S. (2007). Lipedema, a frequently unrecognized problem. J. Am. Acad. Dermatol. 57(2 Suppl.), S1-S3. doi: 10. 1016/j.jaad.2006.09.023

Formolo, D. A., Gaspar, J. M., Melo, H. M., Eichwald, T., Zepeda, R. J., Latini, A., et al. (2019). Deep brain stimulation for obesity: a review and future directions. Front. Neurosci. 13:323. doi: 10.3389/fnins.2019.00323

Frontera, W. R., and Ochala, J. (2015). Skeletal muscle: a brief review of structure and function. Calcif. Tissue Int. 96, 183-195. doi: 10.1007/s00223-014-9915-y

Galeeva, A., Treuter, E., Tomarev, S., and Pelto-Huikko, M. (2007). A prosperorelated homeobox gene Prox-1 is expressed during postnatal brain development as well as in the adult rodent brain. Neuroscience 146, 604-616. doi: 10.1016/j. neuroscience.2007.02.002

Garcia Nores, G. D., Cuzzone, D. A., Albano, N. J., Hespe, G. E., Kataru, R. P., Torrisi, J. S., et al. (2016). Obesity but not high-fat diet impairs lymphatic function. Int. J. Obes. 40, 1582-1590. doi: 10.1038/ijo.2016.96

Geng, X., Cha, B., Mahamud, M. R., and Srinivasan, R. S. (2017). Intraluminal valves: development, function and disease. Dis. Model. Mech. 10, 1273-1287. doi: $10.1242 / \mathrm{dmm} .030825$

Ghanta, S., Cuzzone, D. A., Torrisi, J. S., Albano, N. J., Joseph, W. J., Savetsky, I. L., et al. (2015). Regulation of inflammation and fibrosis by macrophages in lymphedema. Am. J. Physiol. Heart Circ. Physiol. 308, H1065-H1077. doi: 10.1152/ajpheart.00598.2014

Godoy Mde, F., Buzato, E., Brigidio, P. A., and Pereira de Godoy, J. M. (2012). Is lymphostasis an aggravant of lipedema? Case Rep. Dermatol. 4, 222-226. doi: $10.1159 / 000342073$

Gordon, K., Schulte, D., Brice, G., Simpson, M. A., Roukens, M. G., van Impel, A., et al. (2013). Mutation in vascular endothelial growth factor-C, a ligand for vascular endothelial growth factor receptor-3, is associated with autosomal dominant milroy-like primary lymphedema. Circ. Res. 112, 956-960. doi: 10. 1161/CIRCRESAHA.113.300350

Gousopoulos, E., Karaman, S., Proulx, S. T., Leu, K., Buschle, D., and Detmar, M. (2017). High-fat diet in the absence of obesity does not aggravate surgically induced lymphoedema in mice. Eur. Surg. Res. 58, 180-192. doi: 10.1159/ 000461579

Grada, A. A., and Phillips, T. J. (2017). Lymphedema: Pathophysiology and clinical manifestations. J. Am. Acad. Dermatol. 77, 1009-1020. doi: 10.1016/j.jaad.2017. 03.022

Greene, A. K., Grant, F. D., and Slavin, S. A. (2012). Lower-extremity lymphedema and elevated body-mass index. N. Engl. J. Med. 366, 2136-2137. doi: 10.1056/ NEJMc1201684

Hagerling, R., Pollmann, C., Andreas, M., Schmidt, C., Nurmi, H., Adams, R. H., et al. (2013). A novel multistep mechanism for initial lymphangiogenesis in mouse embryos based on ultramicroscopy. EMBO J. 32, 629-644. doi: 10.1038/ emboj.2012.340

Hamet, P., Haloui, M., Harvey, F., Marois-Blanchet, F. C., Sylvestre, M. P., Tahir, M. R., et al. (2017). PROX1 gene CC genotype as a major determinant of early onset of type 2 diabetes in slavic study participants from action in diabetes and vascular disease: preterax and diamicron MR controlled evaluation study. J. Hypertens. 35(Suppl. 1), S24-S32. doi: 10.1097/HJH.0000000000001241

Hammond, R. A., and Levine, R. (2010). The economic impact of obesity in the United States. Diabetes Metab. Syndr. Obes. 3, 285-295. doi: 10.2147/DMSOTT. S7384

Harvey, N. L., Srinivasan, R. S., Dillard, M. E., Johnson, N. C., Witte, M. H., Boyd, K., et al. (2005). Lymphatic vascular defects promoted by Prox1 haploinsufficiency cause adult-onset obesity. Nat. Genet. 37, 1072-1081. doi: $10.1038 /$ ng 1642

Helyer, L. K., Varnic, M., Le, L. W., Leong, W., and McCready, D. (2010). Obesity is a risk factor for developing postoperative lymphedema in breast cancer patients. Breast J. 16, 48-54. doi: 10.1111/j.1524-4741.2009.00855.x

Herzog, Y., Kalcheim, C., Kahane, N., Reshef, R., and Neufeld, G. (2001). Differential expression of neuropilin-1 and neuropilin-2 in arteries and veins. Mech. Dev. 109, 115-119. doi: 10.1016/s0925-4773(01)00518-4

Hespe, G. E., Kataru, R. P., Savetsky, I. L., Garcia Nores, G. D., Torrisi, J. S., Nitti, M. D., et al. (2016). Exercise training improves obesity-related lymphatic dysfunction. J. Physiol. 594, 4267-4282. doi: 10.1113/JP271757

Hill, J. O., Wyatt, H. R., and Peters, J. C. (2012). Energy balance and obesity. Circulation 126, 126-132. doi: 10.1161/CIRCULATIONAHA.111.087213

Ikomi, F., Hunt, J., Hanna, G., and Schmid-Schonbein, G. W. (1996). Interstitial fluid, plasma protein, colloid, and leukocyte uptake into initial lymphatics. J. Appl. Physiol. 81, 2060-2067. doi: 10.1152/jappl.1996.81.5.2060

Jurisic, G., Maby-El Hajjami, H., Karaman, S., Ochsenbein, A. M., Alitalo, A., Siddiqui, S. S., et al. (2012). An unexpected role of semaphorin3a-neuropilin1 signaling in lymphatic vessel maturation and valve formation. Circ. Res. 111, 426-436. doi: 10.1161/CIRCRESAHA.112.269399

Kaipainen, A., Korhonen, J., Mustonen, T., van Hinsbergh, V. W., Fang, G. H., Dumont, D., et al. (1995). Expression of the fms-like tyrosine kinase 4 gene becomes restricted to lymphatic endothelium during development. Proc. Natl. Acad. Sci. U.S.A. 92, 3566-3570. doi: 10.1073/pnas.92.8.3566

Karaman, S., Hollmen, M., Robciuc, M. R., Alitalo, A., Nurmi, H., Morf, B., et al. (2015). Blockade of VEGF-C and VEGF-D modulates adipose tissue inflammation and improves metabolic parameters under high-fat diet. Mol. Metab. 4, 93-105. doi: 10.1016/j.molmet.2014.11.006

Karaman, S., Hollmen, M., Yoon, S. Y., Alkan, H. F., Alitalo, K., Wolfrum, C., et al. (2016). Transgenic overexpression of VEGF-C induces weight gain and insulin resistance in mice. Sci. Rep. 6:31566. doi: 10.1038/srep31566

Karkkainen, M. J., Haiko, P., Sainio, K., Partanen, J., Taipale, J., Petrova, T. V., et al. (2004). Vascular endothelial growth factor $C$ is required for sprouting of the first lymphatic vessels from embryonic veins. Nat. Immunol. 5, 74-80. doi: 10.1038/ni1013

Karkkainen, M. J., Saaristo, A., Jussila, L., Karila, K. A., Lawrence, E. C., Pajusola, K., et al. (2001). A model for gene therapy of human hereditary lymphedema. Proc. Natl. Acad. Sci. U.S.A. 98, 12677-12682. doi: 10.1073/pnas.22144 9198

Kawasaki, T., Kitsukawa, T., Bekku, Y., Matsuda, Y., Sanbo, M., Yagi, T., et al. (1999). A requirement for neuropilin-1 in embryonic vessel formation. Development 126, 4895-4902.

Kitsukawa, T., Shimono, A., Kawakami, A., Kondoh, H., and Fujisawa, H. (1995). Overexpression of a membrane protein, neuropilin, in chimeric mice causes anomalies in the cardiovascular system, nervous system and limbs. Development 121, 4309-4318.

Kivela, R., Salmela, I., Nguyen, Y. H., Petrova, T. V., Koistinen, H. A., Wiener, Z., et al. (2016). The transcription factor Proxl is essential for satellite cell differentiation and muscle fibre-type regulation. Nat. Commun. 7:13124. doi: 10.1038/ncomms13124

Kolodkin, A. L., Levengood, D. V., Rowe, E. G., Tai, Y. T., Giger, R. J., and Ginty, D. D. (1997). Neuropilin is a semaphorin III receptor. Cell 90, 753-762. doi: 10.1016/s0092-8674(00)80535-8

Kretowski, A., Adamska, E., Maliszewska, K., Wawrusiewicz-Kurylonek, N., Citko, A., Goscik, J., et al. (2015). The rs340874 PROX1 type 2 diabetes mellitus risk variant is associated with visceral fat accumulation and alterations in 
postprandial glucose and lipid metabolism. Genes Nutr. 10:4. doi: 10.1007/ s12263-015-0454-6

Kwon, S., Jeon, J. S., Kim, S. B., Hong, Y. K., Ahn, C., Sung, J. S., et al. (2016). Rapamycin up-regulates triglycerides in hepatocytes by down-regulating Prox1. Lipids Health Dis. 15:41. doi: 10.1186/s12944-016-0211-x

Lammoglia, G. M., Van Zandt, C. E., Galvan, D. X., Orozco, J. L., Dellinger, M. T., and Rutkowski, J. M. (2016). Hyperplasia, de novo lymphangiogenesis, and lymphatic regression in mice with tissue-specific, inducible overexpression of murine VEGF-D. Am. J. Physiol. Heart Circ. Physiol. 311, H384-H394. doi: 10.1152/ajpheart.00208.2016

Lavado, A., Lagutin, O. V., Chow, L. M., Baker, S. J., and Oliver, G. (2010). Prox1 is required for granule cell maturation and intermediate progenitor maintenance during brain neurogenesis. PLoS Biol. 8:e1000460. doi: 10.1371/journal.pbio. 1000460

Lavado, A., and Oliver, G. (2007). Prox1 expression patterns in the developing and adult murine brain. Dev. Dyn. 236, 518-524. doi: 10.1002/dvdy.21024

Lecompte, S., Pasquetti, G., Hermant, X., Grenier-Boley, B., Gonzalez-Gross, M., De Henauw, S., et al. (2013). Genetic and molecular insights into the role of PROX1 in glucose metabolism. Diabetes Metab. Res. Rev. 62, 1738-1745. doi: $10.2337 / \mathrm{db} 12-0864$

Lee, D. K., Cheng, R., Nguyen, T., Fan, T., Kariyawasam, A. P., Liu, Y., et al. (2000). Characterization of apelin, the ligand for the APJ receptor. J. Neurochem. 74, 34-41. doi: 10.1046/j.1471-4159.2000.0740034.x

Leibel, R. L., Rosenbaum, M., and Hirsch, J. (1995). Changes in energy expenditure resulting from altered body weight. N. Engl. J. Med. 332, 621-628. doi: 10.1056/ NEJM199503093321001

Levi, B., Glotzbach, J. P., Sorkin, M., Hyun, J., Januszyk, M., Wan, D. C., et al. (2013). Molecular analysis and differentiation capacity of adipose-derived stem cells from lymphedema tissue. Plast. Reconstr. Surg. 132, 580-589. doi: 10.1097/ PRS.0b013e31829ace13

Li, L., Yang, G., Li, Q., Tang, Y., Yang, M., Yang, H., et al. (2006). Changes and relations of circulating visfatin, apelin, and resistin levels in normal, impaired glucose tolerance, and type 2 diabetic subjects. Exp. Clin. Endocrinol. Diabetes 114, 544-548. doi: 10.1055/s-2006-948309

Lim, H. Y., Rutkowski, J. M., Helft, J., Reddy, S. T., Swartz, M. A., Randolph, G. J., et al. (2009). Hypercholesterolemic mice exhibit lymphatic vessel dysfunction and degeneration. Am. J. Pathol. 175, 1328-1337. doi: 10.2353/ajpath.2009. 080963

Lohrmann, C., Foeldi, E., and Langer, M. (2009). MR imaging of the lymphatic system in patients with lipedema and lipo-lymphedema. Microvasc. Res. 77, 335-339. doi: 10.1016/j.mvr.2009.01.005

Martel, C., Li, W., Fulp, B., Platt, A. M., Gautier, E. L., Westerterp, M., et al. (2013). Lymphatic vasculature mediates macrophage reverse cholesterol transport in mice. J. Clin. Invest. 123, 1571-1579. doi: 10.1172/JCI63685

Mehrara, B. J., and Greene, A. K. (2014). Lymphedema and obesity: is there a link? Plast. Reconstr. Surg. 134, 154e-160e. doi: 10.1097/PRS.0000000000000268

Neufeld, G., and Kessler, O. (2008). The semaphorins: versatile regulators of tumour progression and tumour angiogenesis. Nat. Rev. Cancer 8, 632-645. doi: $10.1038 / \mathrm{nrc} 2404$

Nicholson, J. K., Holmes, E., Kinross, J., Burcelin, R., Gibson, G., Jia, W., et al. (2012). Host-gut microbiota metabolic interactions. Science 336, 1262-1267. doi: $10.1126 /$ science. 1223813

Nitti, M. D., Hespe, G. E., Kataru, R. P., Garcia Nores, G. D., Savetsky, I. L., Torrisi, J. S., et al. (2016). Obesity-induced lymphatic dysfunction is reversible with weight loss. J. Physiol. 594, 7073-7087. doi: 10.1113/JP273061

Nurmi, H., Saharinen, P., Zarkada, G., Zheng, W., Robciuc, M. R., and Alitalo, K. (2015). VEGF-C is required for intestinal lymphatic vessel maintenance and lipid absorption. EMBO Mol. Med. 7, 1418-1425. doi: 10.15252/emmm. 201505731

Ogden, C. L., Carroll, M. D., Kit, B. K., and Flegal, K. M. (2013). Prevalence of obesity among adults: United States, 2011-2012. NCHS Data Brief. 2013, 1-8.

Oliver, G., and Srinivasan, R. S. (2008). Lymphatic vasculature development: current concepts. Ann. N. Y. Acad. Sci. 1131, 75-81. doi: 10.1196/annals. 1413.006

Panchik, D., Masco, S., Zinnikas, P., Hillriegel, B., Lauder, T., Suttmann, E., et al. (2019). Effect of exercise on breast cancer-related lymphedema: what the lymphatic surgeon needs to know. J. Reconstr. Microsurg. 35, 37-45. doi: $10.1055 / \mathrm{s}-0038-1660832$
Paul, L., Walker, E. M., Drosos, Y., Cyphert, H. A., Neale, G., Stein, R., et al. (2016). Lack of Prox1 downregulation disrupts the expansion and maturation of postnatal murine beta-cells. Diabetes Metab. Res. Rev. 65, 687-698. doi: $10.2337 / \mathrm{db} 15-0713$

Perala, N., Sariola, H., and Immonen, T. (2012). More than nervous: the emerging roles of plexins. Differentiation 83, 77-91. doi: 10.1016/j.diff.2011.08.001

Petrova, T. V., and Koh, G. Y. (2018). Organ-specific lymphatic vasculature: from development to pathophysiology. J. Exp. Med. 215, 35-49. doi: 10.1084/jem. 20171868

Procino, A. (2014). Overexpression of Prox-1 gene in omental adipose tissue and adipocytes compared with subcutaneous adipose tissue and adipocytes in healthy patients. Cell Biol. Int. 38, 888-891. doi: 10.1002/cbin.10273

Randolph, G. J., Angeli, V., and Swartz, M. A. (2005). Dendritic-cell trafficking to lymph nodes through lymphatic vessels. Nat. Rev. Immunol. 5, 617-628. doi: $10.1038 /$ nri1670

Randolph, G. J., and Miller, N. E. (2014). Lymphatic transport of high-density lipoproteins and chylomicrons. J. Clin. Invest. 124, 929-935. doi: 10.1172/ JCI71610

Rockson, S. G., Keeley, V., Kilbreath, S., Szuba, A., and Towers, A. (2019). Cancerassociated secondary lymphoedema. Nat. Rev. Dis. Primers 5:22. doi: 10.1038/ s41572-019-0072-5

Rouhani, S. J., Eccles, J. D., Tewalt, E. F., and Engelhard, V. H. (2014). Regulation of T-cell Tolerance by Lymphatic Endothelial Cells. J. Clin. Cell Immunol. 5:1000242. doi: $10.4172 / 2155-9899.1000242$

Russell-Jones, D., and Khan, R. (2007). Insulin-associated weight gain in diabetescauses, effects and coping strategies. Diabetes. Obes. Metab. 9, 799-812. doi: 10.1111/j.1463-1326.2006.00686.x

Savetsky, I. L., Albano, N. J., Cuzzone, D. A., Gardenier, J. C., Torrisi, J. S., Garcia Nores, G. D., et al. (2015). Lymphatic function regulates contact hypersensitivity dermatitis in obesity. J. Invest. Dermatol. 135, 2742-2752. doi: 10.1038/jid.2015.283

Savetsky, I. L., Torrisi, J. S., Cuzzone, D. A., Ghanta, S., Albano, N. J., Gardenier, J. C., et al. (2014). Obesity increases inflammation and impairs lymphatic function in a mouse model of lymphedema. Am. J. Physiol. Heart Circ. Physiol. 307, H165-H172. doi: 10.1152/ajpheart.00244.2014

Sawane, M., Kajiya, K., Kidoya, H., Takagi, M., Muramatsu, F., and Takakura, N. (2013). Apelin inhibits diet-induced obesity by enhancing lymphatic and blood vessel integrity. Diabetes Metab. Res. Rev. 62, 1970-1980. doi: 10.2337/db120604

Scallan, J. P., Hill, M. A., and Davis, M. J. (2015). Lymphatic vascular integrity is disrupted in type 2 diabetes due to impaired nitric oxide signalling. Cardiovasc. Res. 107, 89-97. doi: 10.1093/cvr/cvv117

Seth, A., Ye, J., Yu, N., Guez, F., Bedford, D. C., Neale, G. A., et al. (2014). Prox1 ablation in hepatic progenitors causes defective hepatocyte specification and increases biliary cell commitment. Development 141, 538-547. doi: 10.1242/dev. 099481

Shavit, E., Wollina, U., and Alavi, A. (2018). Lipoedema is not lymphoedema: A review of current literature. Int. Wound J. 15, 921-928. doi: 10.1111/iwj. 12949

Shimizu, Y., Shibata, R., Ishii, M., Ohashi, K., Kambara, T., Uemura, Y., et al. (2013). Adiponectin-mediated modulation of lymphatic vessel formation and lymphedema. J. Am. Heart Assoc. 2:e000438. doi: 10.1161/JAHA.113.000438

Silha, J. V., Krsek, M., Sucharda, P., and Murphy, L. J. (2005). Angiogenic factors are elevated in overweight and obese individuals. Int. J. Obes. 29, 1308-1314. doi: $10.1038 /$ sj.ijo.0802987

Soker, S., Takashima, S., Miao, H. Q., Neufeld, G., and Klagsbrun, M. (1998). Neuropilin-1 is expressed by endothelial and tumor cells as an isoform-specific receptor for vascular endothelial growth factor. Cell 92, 735-745. doi: 10.1016/ s0092-8674(00)81402-6

Sosa-Pineda, B., Wigle, J. T., and Oliver, G. (2000). Hepatocyte migration during liver development requires Prox1. Nat. Genet. 25, 254-255. doi: 10.1038/76996

Suh, S. H., Choe, K., Hong, S. P., Jeong, S. H., Makinen, T., Kim, K. S., et al. (2019). Gut microbiota regulates lacteal integrity by inducing VEGF-C in intestinal villus macrophages. EMBO Rep. 20:e46927. doi: 10.15252/embr.201846927

Tammela, T., and Alitalo, K. (2010). Lymphangiogenesis: molecular mechanisms and future promise. Cell 140, 460-476. doi: 10.1016/j.cell.2010.01.045

Tatemoto, K., Hosoya, M., Habata, Y., Fujii, R., Kakegawa, T., Zou, M. X., et al. (1998). Isolation and characterization of a novel endogenous peptide ligand 
for the human APJ receptor. Biochem. Biophys. Res. Commun. 251, 471-476. doi: 10.1006/bbrc. 1998.9489

Tchernof, A., and Despres, J. P. (2013). Pathophysiology of human visceral obesity: an update. Physiol. Rev. 93, 359-404. doi: 10.1152/physrev.00033.2011

Torre, Y. S., Wadeea, R., Rosas, V., and Herbst, K. L. (2018). Lipedema: friend and foe. Horm. Mol. Biol. Clin. Investig. 33:20170076. doi: 10.1515/hmbci-20170076

Torrisi, J. S., Hespe, G. E., Cuzzone, D. A., Savetsky, I. L., Nitti, M. D., Gardenier, J. C., et al. (2016). Inhibition of inflammation and iNOS improves lymphatic function in obesity. Sci. Rep. 6:19817. doi: 10.1038/srep19817

Trayhurn, P., Bing, C., and Wood, I. S. (2006). Adipose tissue and adipokinesenergy regulation from the human perspective. J. Nutr. 136(7 Suppl.), 1935S1939S. doi: 10.1093/jn/136.7.1935S

Triacca, V., Guc, E., Kilarski, W. W., Pisano, M., and Swartz, M. A. (2017). Transcellular pathways in lymphatic endothelial cells regulate changes in solute transport by fluid stress. Circ. Res. 120, 1440-1452. doi: 10.1161/CIRCRESAHA. 116.309828

Tso, P., and Balint, J. A. (1986). Formation and transport of chylomicrons by enterocytes to the lymphatics. Am. J. Physiol. 250(6 Pt 1), G715-G726. doi: 10.1152/ajpgi.1986.250.6.G715

van der Klaauw, A. A., Croizier, S., Mendes de Oliveira, E., Stadler, L. K. J., Park, S., Kong, Y., et al. (2019). Human semaphorin 3 variants link melanocortin circuit development and energy balance. Cell 176, 729.e18-742.e18. doi: 10.1016/j.cell. 2018.12.009

von der Weid, P. Y. (2019). Lymphatic vessel pumping. Adv. Exp. Med. Biol. 1124, 357-377. doi: 10.1007/978-981-13-5895-1_15

von der Weid, P. Y., and Zawieja, D. C. (2004). Lymphatic smooth muscle: the motor unit of lymph drainage. Int. J. Biochem. Cell Biol. 36, 1147-1153. doi: 10.1016/j.biocel.2003.12.008

Wada, H., Ura, S., Kitaoka, S., Satoh-Asahara, N., Horie, T., Ono, K., et al. (2011). Distinct characteristics of circulating vascular endothelial growth factor-a and C levels in human subjects. PLoS One 6:e29351. doi: 10.1371/journal.pone. 0029351

Wade, A. J., Marbut, M. M., and Round, J. M. (1990). Muscle fibre type and aetiology of obesity. Lancet 335, 805-808. doi: 10.1016/0140-6736(90)90933-v

Warren Peled, A., and Kappos, E. A. (2016). Lipedema: diagnostic and management challenges. Int. J. Womens Health 8, 389-395. doi: 10.2147/IJWH. S106227

Weitman, E. S., Aschen, S. Z., Farias-Eisner, G., Albano, N., Cuzzone, D. A., Ghanta, S., et al. (2013). Obesity impairs lymphatic fluid transport and dendritic cell migration to lymph nodes. PLoS One 8:e70703. doi: 10.1371/journal.pone. 0070703

Wellen, K. E., and Hotamisligil, G. S. (2005). Inflammation, stress, and diabetes. J. Clin. Invest. 115, 1111-1119. doi: 10.1172/JCI25102
Werner, R. S., McCormick, B., Petrek, J., Cox, L., Cirrincione, C., Gray, J. R., et al. (1991). Arm edema in conservatively managed breast cancer: obesity is a major predictive factor. Radiology 180, 177-184. doi: 10.1148/radiology.180.1. 2052688

Westmoreland, J. J., Kilic, G., Sartain, C., Sirma, S., Blain, J., Rehg, J., et al. (2012). Pancreas-specific deletion of Prox 1 affects development and disrupts homeostasis of the exocrine pancreas. Gastroenterology 142, 999.e6-1009.e6. doi: 10.1053/j.gastro.2011.12.007

Whelan, T. J., Olivotto, I. A., Parulekar, W. R., Ackerman, I., Chua, B. H., Nabid, A., et al. (2015). Regional nodal irradiation in early-stage breast cancer. N. Engl. J. Med. 373, 307-316. doi: 10.1056/NEJMoa1415340

Wigle, J. T., and Oliver, G. (1999). Prox1 function is required for the development of the murine lymphatic system. Cell 98, 769-778. doi: 10.1016/s0092-8674(00) 81511-1

Wong, B. W., Wang, X., Zecchin, A., Thienpont, B., Cornelissen, I., Kalucka, J., et al. (2017). The role of fatty acid beta-oxidation in lymphangiogenesis. Nature 542, 49-54. doi: 10.1038/nature21028

Yao, L. C., Baluk, P., Srinivasan, R. S., Oliver, G., and McDonald, D. M. (2012). Plasticity of button-like junctions in the endothelium of airway lymphatics in development and inflammation. Am. J. Pathol. 180, 2561-2575. doi: 10.1016/j. ajpath.2012.02.019

Yuan, L., Moyon, D., Pardanaud, L., Breant, C., Karkkainen, M. J., Alitalo, K., et al. (2002). Abnormal lymphatic vessel development in neuropilin 2 mutant mice. Development 129, 4797-4806.

Zhang, F., Zarkada, G., Han, J., Li, J., Dubrac, A., Ola, R., et al. (2018). Lacteal junction zippering protects against diet-induced obesity. Science 361, 599-603. doi: 10.1126/science.aap9331

Zhao, P., Wong, K. I., Sun, X., Reilly, S. M., Uhm, M., Liao, Z., et al. (2018). TBK1 at the crossroads of inflammation and energy homeostasis in adipose tissue. Cell 172 731.e12-743 e12. doi: 10.1016/j.cell.2018.01.007

Zurlo, F., Larson, K., Bogardus, C., and Ravussin, E. (1990). Skeletal muscle metabolism is a major determinant of resting energy expenditure. J. Clin. Invest. 86, 1423-1427. doi: 10.1172/JCI114857

Conflict of Interest: The authors declare that the research was conducted in the absence of any commercial or financial relationships that could be construed as a potential conflict of interest.

Copyright (c) 2020 Ho and Srinivasan. This is an open-access article distributed under the terms of the Creative Commons Attribution License (CC BY). The use, distribution or reproduction in other forums is permitted, provided the original author(s) and the copyright owner(s) are credited and that the original publication in this journal is cited, in accordance with accepted academic practice. No use, distribution or reproduction is permitted which does not comply with these terms. 